\title{
Chlorine determination in medicinal plants by potentiometry with ion-selective electrode after microwave-induced combustion
}

\author{
Mariele S. Nascimento ${ }^{1}$, Gabriel T. Druzian ${ }^{1}$, Rochele S. Picoloto ${ }^{1}$, Paola A. Mello ${ }^{1}$, Erico M. M. Flores ${ }^{1 *}$ \\ ${ }^{1}$ Universidade Federal de Santa Maria - UFSM- Santa Maria, Brazil \\ *Corresponding author: ericommf@gmail.com
}

\begin{abstract}
A method based on microwave-induced combustion (MIC) was applied for medicinal plants digestion allowing further chlorine determination by potentiometry using ion-selective electrode (ISE). Sample masses ranging from 500 to 1000 mg were evaluated for MIC digestion. Water and 10, 25, 50, and $100 \mathrm{mmol} \mathrm{L}^{-1} \mathrm{NH}_{4} \mathrm{OH}$ were investigated as absorbing solutions. The accuracy of the proposed method was evaluated by using certified reference materials (CRMs), by recovery experiments $\left(500 \mu \mathrm{g} \mathrm{g}^{-1}\right)$, and also by comparison with the results obtained by inductively coupled plasma optical emission spectrometry (ICP-OES) after microwave-assisted alkaline extraction (MAE). Using water or $\mathrm{NH}_{4} \mathrm{OH}$ solutions $\left(10\right.$ to $\left.100 \mathrm{mmol} \mathrm{L}^{-1}\right)$, recoveries close to $100 \%$ and relative standard deviation lower than $5 \%$ were obtained. Results were in agreement with CRMs values (better than 95\%) and also with those values obtained by using the MAE method. The main advantage of the proposed method was the complete combustion of high sample mass (1000 mg) resulting in low quantification limit $\left(12.5 \mu \mathrm{g} \mathrm{g}^{-1}\right)$ and chlorine determination at low concentration by ISE. Another advantage of the proposed method was the high chlorine stability in digests (up to 30 days of storage) even using water as absorbing solution, which is in agreement with green analytical chemistry recommendations. Finally, the proposed MIC method was applied for commercial medicinal plants and the chlorine concentration was in the range of $59.4 \pm 1.4$ to $2038 \pm 70 \mu \mathrm{g} \mathrm{g}^{-1}$. The proposed MIC method was considered suitable for quality control for chlorine determination in medicinal plants.
\end{abstract}

Keywords: Medicinal plants, chlorine, MIC, ISE.

https://doi.org/10.22456/2527-2616.108933

\section{Introduction}

It is known that the use of plants for medicinal purposes date approximately 60000 years ago. Nowadays, their use still have an important role in traditional medicine, being widely employed as raw material in the pharmaceutical industry (1). The medicaments from plants have been well accepted by consumers once they assumed that natural products present less toxicity (2). However, plants are not completely free from toxic metabolites, metals, and halogens from environmental, soil, pesticides, among other sources (3).

Chlorine is considered an auxiliary micronutrient in photosynthesis processes on plants development (4). However, when absorbed in large amounts, can be toxic to plant tissues (4). Concerning to the human intake, generally it is associated with sodium in many types of food and is well known that chlorine plays an essential role in cells of organism $(5,6)$. In this way, the World Health Organization (WHO) has been recommended the intake ranging from 125 to $550 \mathrm{mg}$ of chlorine per day (7). However, some studies have reported that chlorine may be more effective than sodium for increasing blood pressure (6), but these mechanisms are still unclear. Taking into account the chlorine importance for plants and human organism, its determination in medicinal plants is essential to ensure a safe product, as well as to provide relevant information about its concentration to consumers.

Among the available techniques, inductively coupled plasma optical emission spectrometry (ICP-OES) (8), inductively coupled plasma mass spectrometry (ICP-MS) (9), ion chromatography (IC) (10), and potentiometry using an ion-selective electrode (ISE) are commonly used for chlorine determination (11). Among these techniques, potentiometry using ISE has low cost-effective and is simpler to use than others (11). However, for the measurements using this technique, chlorine ions must be quantitatively recovered in an appropriate solution. In this sense, sample preparation methods allowing this condition are necessary $(5,12)$.

The Association of Association of Official Agricultural Chemists International (AOAC, 928.04A method) recommends a method based on extraction of chlorine from plants by using a $5 \% \mathrm{Na}_{2} \mathrm{CO}_{3}$ solution followed by calcination at $\leq 500{ }^{\circ} \mathrm{C}$, and solubilization of residue in a $2.8 \mathrm{~mol} \mathrm{~L}^{-1} \mathrm{HNO}_{3}$. The chlorine determination can be performed by using gravimetry or volumetry $(928.04 \mathrm{~B}$ and 915.01 methods) (13). However, this method is subject to some drawbacks, such as losses of chlorine species through volatilization and also contamination since acids and open vessels are used $(5,11)$.

In this context, other sample preparation methods, such as microwave-assisted alkaline extraction (MAE) (9), oxygen flask $(12,14)$, combustion bomb (15), and pyrohydrolysis (11) can be used for this purpose. However, disadvantages associated to interferences due to the high carbon content in solution (MAE), the use of relatively low sample mass (oxygen flask), and low throughput (pyrohydrolysis, oxygen flask and combustion bomb) (11) can be cited.

In order to overcome these drawbacks, microwaveinduced combustion (MIC) has been proposed for an effective digestion of several matrices (16-18). The MIC method involves the use of quartz holder containing a sample pellet, a disc of filter paper, and the use of $50 \mu \mathrm{L}$ 
of $6 \mathrm{~mol} \mathrm{~L}^{-1} \mathrm{NH}_{4} \mathrm{NO}_{3}$ igniter solution, which is introduced inside a quartz vessel. After, the vessel is closed, fixed in a rotor, pressurized with oxygen, and the ignition of combustion is performed by applying microwave irradiation $(11,19)$. After sample combustion, the analytes are retained in a suitable absorbing solution for further analytes determination by using a several techniques (5, $11,20)$. One of the main advantages of the MIC method is the possibility of burning a high sample mass, allowing the analytes determination at low concentration. Other advantages, such as low risk of contamination, high throughput, and the possibility to the use of water or diluted alkaline solutions to absorption of the chlorine avoiding losses by volatilization, can be mentioned (11, 19).

In this context, the purpose of the present study was to demonstrate the suitability of the MIC method for medicinal plants digestion for further chlorine determination by potentiometry using a simple and inexpensive technique as ion-selective electrode (ISE). Water and $\mathrm{NH}_{4} \mathrm{OH}$ solutions were evaluated for analytes absorption after the MIC method. Additionally, a study was performed during a period of thirty days in order to evaluate the stability of chlorine in the investigated absorbing solutions. The accuracy of MIC method was evaluated by using certified reference materials (CRMs), by recoveries experiments and, by comparing with those results obtained after the MAE method and chlorine determination by ICP-OES. Additionally, a method recommended by AOAC (928.04A) was applied in order to evaluate its adequability for further chlorine determination in medicinal plants by ISE.

\section{Experimental section}

\section{Instrumentation}

The MIC and MAE methods were performed by using the same microwave oven (Multiwave 3000, Microwave Sample Preparation System, Anton Paar, Austria) equipped with eight high-pressure quartz vessels with 80 $\mathrm{mL}$ of internal volume. The maximum temperature and pressure allowed using this system were $280{ }^{\circ} \mathrm{C}$ and 80 bar, respectively. The software version used was v1.27 (previously modified to run with a maximum pressure rate of 3 bar s$^{-1}$ and not the original 0.8 bar s$^{-1}$ value). For MIC method, commercial quartz holders (Anton Paar, part number 16427) were used to support the filter paper and the sample inside of the quartz vessels. A muffle furnace (LF0913, Jung, Brazil) was used for the AOAC method and platinum crucibles (capacity of $50 \mathrm{~mL}$ ) were used for this sample preparation method.

Before the use of MIC, MAE, and AOAC methods, samples and CRMs were ground using a mill (Model A 11 $\mathrm{B}$, IKA ${ }^{\circledR}$, China), dried in an oven at $105^{\circ} \mathrm{C}$, for $120 \mathrm{~min}$ and pressed as pellets (diameter of $13 \mathrm{~mm}$ ) using a hydraulic press set at 3 ton (Specac, England). An analytical balance (model AY 220, max. $220 \mathrm{~g}, 0.0001 \mathrm{~g}$, Shimadzu, Japan) was used for sample weighing.

Chlorine determination was carried out using a potentiometer (Model 7.1 pH/Ion meter, Metrohm,
Switzerland) equipped with an ion-selective electrode (Model 6.0502.120, Metrohm) and reference electrode of $\mathrm{Ag} / \mathrm{AgCl}$ (Model 6.0726.100, Metrohm). An inductively coupled plasma optical emission spectrometer with axial view configuration (Spectro Ciros CCD simultaneous spectrometer, Spectro Analytical Instruments, Germany) was used for chlorine determination in solutions obtained after the MAE method, which was used for comparison of results.

The same equipment was used for carbon determination in final solutions obtained after MIC, MAE and AOAC methods. This spectrometer was operated with a crossflow nebulizer (TQ-30-A3, Meinhard, USA) and a Scotttype double pass spray chamber (Glass Expansion, Australia). The argon flow rate (with 99.998\%, White Martins-Praxair, Brazil) used for plasma, auxiliary, and nebulization gas was set to $14.0,1.0$ and $1.00 \mathrm{~L} \mathrm{~min}^{-1}$, respectively. Radiofrequency power was set to 1550 and $1400 \mathrm{~W}$ for chlorine and carbon determination, respectively. The monitored wavelength for chlorine, carbon, and yttrium (used as internal standard during carbon measurements) were 134.724, 193.091, and $371.029 \mathrm{~nm}$, respectively.

\section{Samples, reagents, and reference solutions}

In this study, nine commercial Brazilian medicinal plants (Achyrocline satureioides - "macela", Aesculus hippocastanum- "horse chestnut", Baccharis halimifolia"carqueja", Illicium verum - "star anise", Melissa officinalis - "Melissa”, Rhamnus purshiana - "cascara sagrada", Tilia cordata- "tilia”, Trigonella foenumgraecum - "fenugreek", and Zingiber officinale "ginger") were purchased in a local drugstore. For the accuracy evaluation, CRMs of apple leaves (NIST 1515) and peach leaves (NIST 1547) from National Institute of Standards and Technology were used.

All the reagents used in this work were of analytical grade. Water obtained from a Milli-Q system $(18.2 \mathrm{M} \Omega \mathrm{cm})$ was used to prepare all standard solutions. The $\mathrm{HNO}_{3}(65 \%$, Merck, Germany) used in the AOAC method was purified by using a sub-boiling distillation system (DuoPur, Milestone, Italy). Concentrated nitric acid (P.A, 65\%, Merck, Germany) was used for cleaning step of quartz vessels and holders. A stock solution containing $10000 \mathrm{mg}$ $\mathrm{L}^{-1}$ of chlorine was prepared by the dissolution of $\mathrm{KCl}$ salt (Merck,) in water and used for to prepare the calibration solutions of ISE and ICP-OES equipment. Calibration solutions for chlorine determination by ISE and ICP-OES (in the range of 250 to $10000 \mu \mathrm{g} \mathrm{L}^{-1}$ and 1 to $10 \mathrm{mg} \mathrm{L}^{-1}$, respectively) were prepared by serial dilution of the stock standard solution in water (ISE) and $10 \mathrm{mmol} \mathrm{L}^{-1} \mathrm{NH}_{4} \mathrm{OH}$ (ICP-OES). For chlorine measurements by ISE, standards and sample solutions were diluted $(1: 1)$ with $1.0 \mathrm{~mol} \mathrm{~L}^{-1}$ $\mathrm{KNO}_{3}$ (Merck) (used as an ionic strength adjuster).

In order to evaluate the digestion efficiency for MIC, carbon in solution was determined by ICP-OES (21). For carbon determination, calibration solutions ( 5 to $500 \mathrm{mg} \mathrm{L}$ ${ }^{1}$ ) were prepared by dilution using a stock solution of 1000 $\mathrm{mg} \mathrm{L}^{-1}$ of $\mathrm{C}$ from citric acid (Dinâmica, Brazil) in water. Yttrium $\left(1 \mathrm{mg} \mathrm{L}^{-1}\right)$ was used as internal standard (Spex 
CertiPrep, $1000 \mathrm{mg} \mathrm{L}^{-1}$, Metuchen, USA) in blanks, standards, and samples. Before analyses, volatile carbon species were removed using Ar flow $0.1 \mathrm{~L} \mathrm{~min}^{-1}$ for $2 \mathrm{~min}$, as recommended in previous study (21).

As igniter for the MIC method, $50 \mu \mathrm{L}$ of $6 \mathrm{~mol} \mathrm{~L}^{-1}$ $\mathrm{NH}_{4} \mathrm{NO}_{3}$ solution were used and this solution was prepared by the dissolution of the respective salt (Merck) in water. A small disc of filter paper $(15 \mathrm{~mm}$ diameter, $14.8 \pm 0.4 \mathrm{mg}$ ) with low ash content (Black Ribbon Ashless, Schleicher \& Schuell GmbH, Dassel, Germany) was used as aid for the combustion process. The filter paper was previously cleaned with ethanol in an ultrasonic bath (P120H, 37 kHz, 330 W, Elma Sonics, Germany) for $40 \mathrm{~min}$, rinsed with water, and dried in a class 100 laminar flow bench (CSLH-12, Veco, Brazil) for $2 \mathrm{~h}$. Absorbing solutions were prepared by dilution of $\mathrm{NH}_{3}(25 \%$, Merck) in water to prepare 10 to $100 \mathrm{mmol} \mathrm{L}^{-1} \mathrm{NH}_{4} \mathrm{OH}$ solutions. The $5 \% \mathrm{Na}_{2} \mathrm{CO}_{3}$ solution (used in the AOAC method) was prepared by dissolution of respective salt (Merck) in water. Tetramethylammonium hydroxide (TMAH, 25\%, Merck) was used in the MAE method.

\section{Sample preparation methods}

\section{Microwave-induced combustion (MIC) method}

For the development of the proposed MIC method, initial experiments were performed using Zingiber officinale. Sample pellets with mass ranging from 0.5 to $1.0 \mathrm{~g}$ were prepared in order to evaluate the maximum sample mass that could be efficiently digested by the MIC method. Samples were placed on the quartz holder containing a filter paper with $50 \mu \mathrm{L}$ of $6 \mathrm{~mol} \mathrm{~L}^{-1} \mathrm{NH}_{4} \mathrm{NO}_{3}$, used as igniter solution. Then, the quartz holders were introduced into the respective quartz vessels containing $6 \mathrm{~mL}$ of absorbing solution. After, vessels were closed, placed on the rotor, and pressurized with oxygen at 20 bar as initial pressure. The rotor containing the vessels was placed inside of the microwave oven and the following microwave-heating program was applied: i) $1400 \mathrm{~W}$ for 5 min (reflux step) and ii) $0 \mathrm{~W}$ for $20 \mathrm{~min}$ (cooling step). Final digests were diluted with water up to $25 \mathrm{~mL}$. After each run, cleaning of vessels and holders was performed with $6 \mathrm{~mL}$ of concentrated $\mathrm{HNO}_{3}$ under microwave irradiation for $10 \mathrm{~min}$ at $1400 \mathrm{~W}$ (reflux step) and $20 \mathrm{~min}$ at $0 \mathrm{~W}$ (cooling step) and the same microwave irradiation program was applied using $6 \mathrm{~mL}$ of water.

\section{Microwave-assisted alkaline extraction (MAE) method}

In order to compare the results obtained after the MIC method, chlorine extraction was performed according to previous studies $(9,22)$. The Zingiber officinale sample was used and sample masses $(0.25 \mathrm{mg})$ were weighed and placed on the quartz vessel and $10 \mathrm{~mL}$ of water and $10 \mathrm{~mL}$ of $25 \%$ TMAH were added. After, vessels were closed and placed in the rotor. The rotor was placed inside of the microwave oven and the following microwave-heating program was applied: i) $1400 \mathrm{~W}$ for $15 \mathrm{~min}$ (ramp of 10 min) and ii) $0 \mathrm{~W}$ for $20 \mathrm{~min}$ (cooling step) (22). After microwave heating program, resultant solutions were diluted with water up to $25 \mathrm{~mL}$, before chlorine determination by ICP-OES. Before measurements, extracts were filtered through $0.45 \mu \mathrm{m}$ of polyvinylidene difluoride (PVDF) membrane (Millex-HV, Millipore) and diluted with water. After each run, the cleaning of vessels was performed using $6 \mathrm{~mL}$ of concentrated $\mathrm{HNO}_{3}$ under microwave irradiation for $10 \mathrm{~min}$ at $1400 \mathrm{~W}$ (reflux step) and $20 \mathrm{~min}$ at $0 \mathrm{~W}$ (cooling step). After the cleaning the vessels holders with water, the same microwave irradiation program was applied using $6 \mathrm{~mL}$ of water.

\section{AOAC method}

In this study, the method recommended by AOAC (928.04A method) was applied (13). Thus, $5.0 \mathrm{~g}$ of the Zingiber officinale sample were weighed, placed in platinum crucible and $20 \mathrm{~mL}$ of $5 \% \mathrm{Na}_{2} \mathrm{CO}_{3}$ solution were added. Thereafter, the samples were placed in a muffle at $\leq 500{ }^{\circ} \mathrm{C}$ for about $2 \mathrm{~h}$. After, the residue was washed with hot water, filtered (filtrate 1) and again placed in a muffle at $\leq 500{ }^{\circ} \mathrm{C}$. The remaining ashes were dissolved using 2.8 mol L $\mathrm{L}^{-1} \mathrm{HNO}_{3}$ and filtered (filtered 2). The solutions corresponding to filtrates 1 and 2 were mixed, filled to 50 $\mathrm{mL}$ in volumetric flasks and then chlorine determination was performed by ISE. The cleaning of the platinum crucible was performed using $20 \mathrm{~mL}$ of $5 \% \mathrm{HNO}_{3}$ and heating at about $100{ }^{\circ} \mathrm{C}$ during $2 \mathrm{~h}$ at $100{ }^{\circ} \mathrm{C}$ in hotplate and, posteriorly, rinsed with water.

\section{Validation of the MIC method}

The validation of the proposed MIC method was performed according to the International Conference on Harmonization (ICH) recommendation (23). The accuracy of the MIC method was evaluated by using two CRMs (NIST 1515 and NIST 1547), and by recovery experiments performed by adding an equivalent concentration of 500 $\mu \mathrm{g} \mathrm{g}^{-1}$ of chlorine on the solid sample before the combustion (corresponding to $50 \mu \mathrm{L}$ of a $10000 \mathrm{mg} \mathrm{L}^{-1}$ solution). Furthermore, the accuracy was also evaluated by comparing the results obtained after the MIC method with those results obtained after the MAE method and chlorine determination by ICP-OES. The limit of quantification (LOQ) for ISE was estimated as follows: $\mathrm{LOQ}=\mathrm{x}+\mathrm{k} \cdot \mathrm{SD}$ (were $\mathrm{x}$ corresponds to the mean of the blank measured, $\mathrm{k}$ corresponds to numerical factor according to the confidence level required $(\mathrm{k}=10)$ and, SD is the standard deviation of ten blank measurements. The linearity was expressed as related coefficients $\left(R^{2}\right)$ of analytical curve. The robustness was evaluated by the variations of important method parameters, as e.g., sample mass, type and concentration of absorbing solution. Regarding to repeatability and the intermediate precision of the proposed MIC method, they were evaluated based on the relative standard deviations (RSDs) by analyzing each solution sample for three days (inter day precision) and with three replicated analysis per day (intra-day precision). The statistical calculations were performed using GraphPad InStat (GraphPad InStat Software Inc, Version $3.00,1997)$ software and a confidence level of $95 \%$ was used. 


\section{Results and Discussion}

\section{Evaluation of the sample mass for the MIC method}

Initial experiments were carried out to evaluate the maximum sample mass to be digested using the proposed MIC method in order to obtain suitable LOQs. Thus, Zingiber officinale sample masses from 500 to $1000 \mathrm{mg}$ were burned and the maximum pressure achieved during the combustion was monitored. These experiments were performed using $50 \mu \mathrm{L}$ of $6 \mathrm{~mol} \mathrm{~L}^{-1} \mathrm{NH}_{4} \mathrm{NO}_{3}$ solution (as aid for combustion) and 20 bar of oxygen (as initial pressure). The maximum pressure value achieved during the combustion using 500,600, 700, 800, 900, and 1000 $\mathrm{mg}$ of sample was 32.1, 32.9, 33.8, 35.7, 37.1, and 38.2 bar, respectively. Using higher sample masses $(1000 \mathrm{mg})$, the maximum pressure achieved during the combustion corresponded around $48 \%$ of the limit recommended by the manufacturer for routine operation (80 bar). When compared with the other sample preparation methods (as combustion bomb and oxygen flasks), the proposed MIC method presented many advantages, such as the possibility of digestion of higher sample masses and high throughput (eight samples can be simultaneously digested). The system used for MIC method contains temperature and pressure control allowing to apply a reflux step after the combustion assuring quantitative recoveries of the analytes $(11,19)$. An important aspect is that even using relatively high sample mass, the digests obtained after the MIC method presented low carbon content (lower than $25 \mathrm{mg}$ $\left.\mathrm{L}^{-1}\right)$. Low carbon content in solutions is important to avoid possible interferences in the chlorine determination by ISE. In addition, it was not needed to apply a dilution step before chlorine measurements by ISE, allowing the chlorine determination by ISE at low concentration. Furthermore, due to the combustion of a relatively high sample mass $(1000 \mathrm{mg})$, it was possible to determine chlorine at low concentration using ISE, an analytical technique relatively simple and of low cost when compared to plasma-based techniques or ion chromatography $(8,9,12)$.

\section{Evaluation of the absorbing solution for the MIC method}

It is well known that the type and the concentration of the absorbing solution for halogen absorption after the MIC method must be carefully evaluated to ensure quantitative results $(11,19)$. Previous studies have reported that the use of water or diluted alkaline solutions can be suitable for halogen absorption after the combustion in a variety of samples $(10,11,17)$.

In order to investigate the suitability of absorbing solution for chlorine determination in medicinal plants by ISE, water and $10,25,50$, and $100 \mathrm{mmol} \mathrm{L}^{-1} \mathrm{NH}_{4} \mathrm{OH}$ solutions were used. Experiments were carried out using $1000 \mathrm{mg}$ of Zingiber officinale, 20 bar of oxygen as initial pressure, and the volume of absorbing solution was set at $6 \mathrm{~mL}$. Recovery experiments were performed by spike of $500 \mu \mathrm{g}$ $\mathrm{g}^{-1}$ of chlorine (corresponding to $50 \mu \mathrm{L}$ of a $10000 \mathrm{mg} \mathrm{L}^{-1}$ solution) on solid samples before the combustion using optimized conditions. The results are shown in Figure 1.

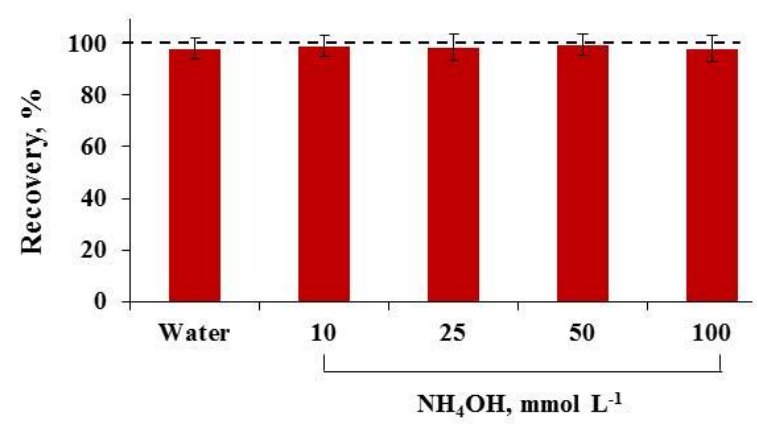

Figure 1. Influence of absorbing solution for chlorine absorption from medicinal plants using $6 \mathrm{~mL}$ of water, 10, 25, 50, and 100 mmol L-1 $\mathrm{NH}_{4} \mathrm{OH}$ solutions, with reflux step of $5 \mathrm{~min}$. Determination was performed by ISE (error bars represent the standard deviation, $\mathrm{n}=3$ ).

As can be seen in Figure 1, recoveries close to $100 \%$ were achieved for chlorine using water or $\mathrm{NH}_{4} \mathrm{OH}$ solutions (10 to $100 \mathrm{mmol} \mathrm{L}^{-1}$ ) and the RSDs were lower than $5 \%$ for all solutions investigated. The use of water or alkaline solutions provided negligible blank values. It is important to mention that the use of water or diluted solutions is an important aspect because can to reduce reagents consumption, as well as laboratory residues generation.

In order to verify the stability of the chlorine in the absorbing solutions investigated, MIC digests were stored in closed polypropylene vessels at $4{ }^{\circ} \mathrm{C}$ for a period ranging from 1 to 30 days. Thus, chlorine was determined by ISE and results are presented in Figure 2. The reference values were the results obtained in the same day MIC that digestion was performed (Day 1).

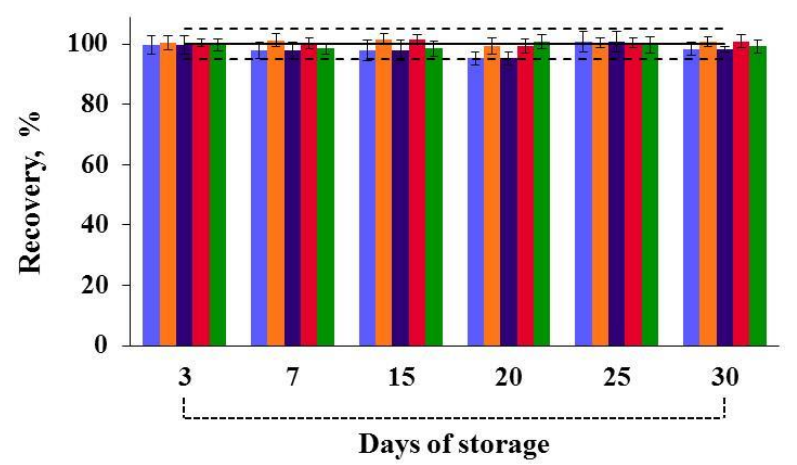

Figure 2. Concentration of chlorine in solutions after MIC

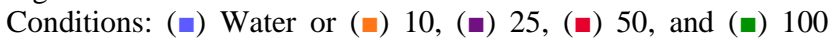
mmol L-1 $\mathrm{NH}_{4} \mathrm{OH}$ as absorbing solution and 5 min of reflux step for $3,7,15,20,25$, and 30 days of storage. Chlorine determination was performed by ISE (error bars represent the standard deviation, $\mathrm{n}=3$ ).

As can be seen in Figure 2, no losses of chlorine were observed up to 30 days of storage, independent on the absorbing solution used (ANOVA, confidence level of 95\%). This relatively long stability, even using water as absorbing solution, can be possible due to the $\mathrm{pH}$ of the final digested obtained after MIC method (about 6) that helps to keep the analyte in solution (17). Additionally, it is reported that the presence of some elements, such as $\mathrm{Ca}$, $\mathrm{K}$, and $\mathrm{Mg}$ (generally present in high concentration in 
botanical samples), may contribute to maintain the halogens into a solution (17). In this way, according to the suitability of the water for chlorine absorption after the MIC method and the high analyte stability in solution, water was chosen as the absorbing solution for the subsequent chlorine determination in medicinal plants by ISE.

\section{AOAC method limitations}

The AOAC 928.04A method for chlorine determination in medicinal plants was evaluated in this study and compared to those using MIC (13). The results obtained for chlorine after the AOAC method agreed to those obtained after the MIC method in about 45\% (630 \pm 40 and $1145 \pm 35 \mu \mathrm{g} \mathrm{g}$ ${ }^{1}$, respectively using the same medicinal plant). This low agreement can be partially explained due to losses of volatile chlorine species at $500{ }^{\circ} \mathrm{C}$ using an open system. Furthermore, it is important to emphasize that the use of acids is not recommended for further halogens determination due to possibility of formation of compounds easily lost by volatilization, as well as interferences during the measurements (5). According to the results, although the AOAC methods has been a common choice for botanical samples, it may not be accurate. This result reinforces the need to develop more accurate and precise sample preparation methods for the subsequent determination of chlorine in plants.

\section{Analytical figures of merit}

The accuracy of the proposed MIC method was evaluated by using two CRMs: apple leaves (NIST 1515) and peach leaves (NIST 1547). Results are shown in Table 1.

Table 1. Results obtained for CRMs after the MIC method using water as absorbing solution. Chlorine determination was performed by ISE ( $\mu \mathrm{g} \mathrm{g}^{-1}$, mean \pm standard deviation, $\mathrm{n}=3$ ).

\begin{tabular}{lcc}
\hline Sample & Reference values & MIC method \\
\hline NIST 1515 & $579 \pm 23$ & $551 \pm 28$ \\
NIST 1547 & $360 \pm 17$ & $349 \pm 12$ \\
\hline
\end{tabular}

As shown in Table 1, an agreement better than $95 \%$ ( $t$-test, 95\% of confidence level) and RSDs below 5\% for both CRMs were obtained. Additionally, the accuracy was also evaluated by comparison of results obtained by ICP-OES after the MAE method (Table 2) and no difference was observed by comparing with the proposed the MIC method (determination by ISE). The LOQ obtained for chlorine by ISE was $12.5 \mu \mathrm{g} \mathrm{g}^{-1}$. The relatively low LOQ can be partially associated to the negligible blank values obtained after the combustion as well as the use of high sample mass $(1000 \mathrm{mg})$. The correlation coefficient $\left(R^{2}\right)$ of calibration curve was 0.990 . This result indicated a good linear response for the evaluated concentration range (250 to $\left.10000 \mu \mathrm{g} \mathrm{L}^{-1}\right)$. The proposed method was considered as robust since the results to small variations of the sample mass (950 to $1050 \mathrm{mg}$ ) and absorbing solution (water or alkaline solution) during measurements by ISE have changing less than $5 \%$, showing no effect on experiments results. For repeatability and intermediate precision, the results obtained were considered suitable since it was also lower than $5 \%$.

\section{Chlorine determination in medicinal plants by ISE after the MIC method}

After optimizing all conditions, the MIC method was applied for nine Brazilian medicinal plants and respective results obtained by ISE are shown in Table 2. For comparison, results obtained using the MAE method and determination by ICP-OES are also shown.

Table 2. Concentration of chlorine in medicinal plants obtained by ISE after the MIC method and ICP-OES after the MAE method (mean and standard deviation, ${\mu \mathrm{g} \mathrm{g}^{-1}, \mathrm{n}=3 \text { ). }}$.

\begin{tabular}{lll}
\hline \multirow{2}{*}{ Sample } & \multicolumn{2}{c}{ Cl concentration } \\
\cline { 2 - 3 } & \multicolumn{1}{c}{ MIC } & MAE \\
\hline Achyrocline satureioides & $1120 \pm 46$ & $1130 \pm 99$ \\
Aesculus hippocastanum & $281 \pm 10$ & $299 \pm 25$ \\
Baccharis halimifolia & $1060 \pm 48$ & $1179 \pm 55$ \\
IIllicium verum & $61.4 \pm 2.5$ & $63.4 \pm 5.2$ \\
Melissa officinalis & $1644 \pm 47$ & $1688 \pm 150$ \\
Rhamnus purshiana & $59.4 \pm 1.4$ & $60.3 \pm 5.6$ \\
Tilia cordata & $313 \pm 5$ & $323 \pm 28$ \\
Trigonella foenum-graecum & $2038 \pm 70$ & $2055 \pm 180$ \\
Zingiber officinale & $1145 \pm 35$ & $1195 \pm 99$ \\
\hline
\end{tabular}

As shown in Table 2, the chlorine concentration in medicinal plants obtained by ISE after MIC method was in the range of 59.4 to $2038 \mu \mathrm{g} \mathrm{g}^{-1}$. The chlorine concentration in the samples investigated in the present study was in agreement to data found in the literature for samples of botanical origin $(8,9,24)$. Results obtained after the MIC method presented no statistical difference ( $t$ test, $95 \%$ of confidence level) in comparison with those obtained after the MAE method (chlorine determination by ICP-OES).

Regarding to MAE method, it was important to mention that the carbon present in final solutions was relatively high, about $6 \mathrm{~g} \mathrm{~L}^{-1}$. In this way, a filtration and a dilution step of around 5 times were required before the chlorine determination by ICP-OES, resulting in an increase of LOQ (62.5 $\left.\mu \mathrm{g} \mathrm{g}^{-1}\right)$. Additionally, chlorine determination by ISE after the MAE method was not possible due to high carbon content in final solutions even after dilutions and filtrations. It is accepted that the presence of high carbon concentration in solution can result in deposition in the interface of electrode, changing its sensitivity and response time of sensor during the analytes measurements (25). In this way, special care should be taken for accurate chlorine measurements by ISE at low concentration, after extraction-based sample preparation methods.

\section{Conclusions}

The proposed MIC method was considered suitable for the decomposition of medicinal plants and further chlorine determination by ISE. The digests obtained after combustion presented low carbon content $\left(<25 \mathrm{mg} \mathrm{L}^{-1}\right)$, avoiding interference by carbon deposits on the electrode membrane surface. Using the same conditions, high analyte stability was obtained (up to 30 days of storage). It 
is important to note that the use of water for chlorine absorption, as well as its high stability are considered important advantages of the proposed method. The proposed method provided a good throughput when compared to the combustion bomb and oxygen flask, since up to eight samples were efficiently digested in only $5 \mathrm{~min}$ by MIC. Another advantage of the proposed method is the use of water or diluted absorbing solutions, which is according with the green analytical chemistry recommendations. Taking into account to the advantages obtained, the MIC method can be considered a suitable alternative for the subsequent determination of chlorine by ISE and can be used in routine analysis for quality control of medicinal plants.

\section{Acknowledgments}

The authors are grateful to Conselho Nacional de Desenvolvimento Científico e Tecnológico (CNPq 420843/2018-3/Universal, 312271/2017-4/PQ), the National Institute of Science \& Technology in Bioanalytics (INCTBio CNPq 465389/2014-7), Fundação de Amparo à Pesquisa do Estado do Rio Grande do Sul (FAPERGS 19/2551-0000702-7/Internac.). This study was financed in part by the Coordenação de Aperfeiçoamento de Pessoal de Nível Superior - Brasil (CAPES) - Finance Code 001.

\section{Conflict of interest}

The authors declare no conflicts of interest.

\section{References}

1. Fabricant DS, Farnsworth NR. The value of plants used in traditional medicine for drug discovery. Environ Health Perspect. 2001;109 Suppl 1:69-75.

2. Ekor M. The growing use of herbal medicines: issues relating to adverse reactions and challenges in monitoring safety. Front. Pharmacol. 2014;4:4-177.

3. Pohl P, Dzimitrowicz A, Jedryczko D, SzymczychaMadeja A, Welna M, Jamroz P. The determination of elements in herbal teas and medicinal plant formulations and their tisanes. J Pharm Biomed Anal. 2016;130:326-35.

4. Chen W, He ZL, Yang XE, Mishra S, Stoffella PJ. Chlorine nutrition of higher plants: Progress and perspectives. J. Plant Nutr. 2010;33(7):943-52.

5. Mesko MF, Costa VC, Picoloto RS, Bizzi CA, Mello PA. Halogen determination in food and biological materials using plasma-based techniques: challenges and trends of sample preparation. J. Anal. At. Spectrom. 2016;31(6):1243-61.

6. McCallum L, Lip S, Padmanabhan S. The hidden hand of chloride in hypertension. Pflugers Arch. 2015;467(3):595-603.

7. Chloride in drinking-water, Background document for development WHO guidelines for drinking-water quality, World Health Organization (WHO), Geneva, 2003.
8. Muller ALH, Bizzi CA, Pereira JSF, Mesko MF, Moraes DP, Flores EMM, et al. Bromine and chlorine determination in cigarette tobacco using microwaveinduced combustion and inductively coupled plasma optical emission spectrometry. J Braz Chem Soc. 2011;22:1649-55.

9. Tagami K, Uchida S, Hirai I, Tsukada H, Takeda H. Determination of chlorine, bromine and iodine in plant samples by inductively coupled plasma-mass spectrometry after leaching with tetramethyl ammonium hydroxide under a mild temperature condition. Anal. Chim. Acta. 2006;570(1):88-92.

10. Muller ALH, Muller CC, Antes FG, Barin JS, Dressler VL, Flores EMM, et al. Determination of bromide, chloride, and fluoride in cigarette tobacco by ion chromatography after microwave-induced combustion. Anal. Lett. 2012;45(9):1004-15.

11. Mello P, Barin J, Duarte F, Bizzi C, Diehl L, Muller E, et al. Analytical methods for the determination of halogens in bioanalytical sciences: a review. Anal. Bioanal. Chem. 2013;405(24):7615-42.

12. Zhang S, Zhao T, Wang J, Qu X, Chen W, Han Y. Determination of fluorine, chlorine and bromine in household products by means of oxygen bomb combustion and ion chromatography. J. Chromatogr. Sci. 2012.

13. Willian Hprwitz, George W. Latimer, Oficial Methods of Analysis of Association of Official Agricultural Chemists International (AOAC), Chapter 3, p. 14 USA, $18^{\text {th }}$ Edition, 2005.

14. Michalski R. Simultaneous determination of common inorganic anions in black and herbal tea by suppressed ion chromatography. J. Food Qual. 2006;29(6):607-16.

15. Fung YS, Dao KL. Oxygen bomb combustion ion chromatography for elemental analysis of heteroatoms in fuel and wastes development. Anal. Chim. Acta. 1995;315(3):347-55.

16. Muller ALH, Mello PA, Mesko MF, Duarte FA, Dressler VL, Muller EI, et al. Bromine and iodine determination in active pharmaceutical ingredients by ICP-MS. J. Anal. At. Spectrom.. 2012;27(11):1889-94.

17. Picoloto RS, Doneda M, Flores ELM, Mesko MF, Flores EMM, Mello PA. Simultaneous determination of bromine and iodine in milk powder for adult and infant nutrition by plasma based techniques after digestion using microwave-induced combustion. Spectrochimica Acta Part B. 2015;107(0):86-92.

18. Silva JS, Diehl LO, Frohlich AC, Costa VC, Mesko MF, Duarte FA, et al. Determination of bromine and iodine in edible flours by inductively coupled plasma mass spectrometry after microwave-induced combustion. Microchem J. 2017;133:246-50.

19. J. S. Barin, E.M.M. Flores, M. F. Mesko, P. A. Mello, J. S. F. Pereira, Chapter 5 - Microwave-Induced Combustion. In: Microwave-Assisted Sample Preparation for Trace Element Analysis, E. M. M. Flores (Ed.); Amsterdam: Elsevier; 2014.

20. Mesko MF, Balbinot FP, Scaglioni PT, Nascimento MS, Picoloto RS, da Costa VC. Determination of halogens and sulfur in honey: a green analytical 
method using a single analysis. Anal. Bioanal. Chem. 2020;412(24):6475-84.

21. Bizzi CA, Barin JS, Muller EI, Schmidt L, Nóbrega JA, Flores EM. Evaluation of oxygen pressurized microwave-assisted digestion of botanical materials using diluted nitric acid. Talanta. 2011;83(5):1324-8.

22. Romarís-Hortas V, Moreda-Piñeiro A, BermejoBarrera P. Microwave assisted extraction of iodine and bromine from edible seaweed for inductively coupled plasma-mass spectrometry determination. Talanta. 2009;79(3):947-52.

23. International Conference on Harmonization (ICH), of Technical Requirements for the Registration of Pharmaceutical for Human Use. Validation of Analytical Procedures: Text and Methodology, Q2 (R1). Geneva, Switzerland, 2005. 17p.

24. Barbosa J, Santos C, dos Santos Bispo L, Lyra F, David J, Korn M, et al. Bromine, Chlorine, and Iodine Determination in Soybean and its Products by ICP-MS After Digestion Using Microwave-Induced Combustion. Food Analytical Methods. 2013;6(4):1065-70.

25. Dimeski G, Badrick T, John AS. Ion Selective Electrodes (ISEs) and interferences--a review. Clin Chim Acta. 2010;411(5-6):309-17. 